\title{
Relationship between water use efficiency (WUE) and production of different wheat genotypes at soil water deficit
}

\author{
Ya-Chen $\mathrm{Hu}^{\mathrm{a}, 1}$, Hong-Bo Shao ${ }^{\mathrm{b}, \mathrm{c}, \mathrm{d}, *, 1}, \mathrm{Li}-\mathrm{Ye} \mathrm{Chu}{ }^{\mathrm{c}}$, Wu Gang ${ }^{\mathrm{e}}$ \\ a Teaching Affairs Department, Jilin Normal University, Siping 13600, Jilin, People's Republic of China \\ ${ }^{\mathrm{b}}$ Center of National Water-saving and Irrigation at Yangling, Centre of Soil and Water Conservation and Eco-environmental Research, \\ The Chinese Academy of Sciences and Northwest A\&F University, Yangling 712100, People's Republic of China \\ c Biology Department, College of Molecular and Chemical Engineering, Qingdao University of Science and Technology, \\ Qingdao 266042, People's Republic of China \\ ${ }^{\mathrm{d}}$ Qingdao Institute of Biomass Energy and Bioprocess Technology, Chinese Academy of Sciences, Qingdao266071, China \\ e State Key Laboratory of Urban and Regional Ecology, Research Center for Eco-environmental Sciences, \\ The Chinese Academy of Sciences, Bejing100085, People's Republic of China
}

Received 1 August 2006; received in revised form 13 September 2006; accepted 1 October 2006 Available online 10 October 2006

\begin{abstract}
Through 2-year field experiments, 7 wheat genotypes were better in their field yield. These 7 wheat genotypes and other 3 wheat species, which are being popularized on a large scale in different locations of China, were selected as experimental materials for the sake of measuring their difference in WUE and production and comparing their relationship at soil water deficits, future more, providing better drought resistance lines and theoretical guide for wheat production and practices and exploring anti-drought physiological mechanisms of different wheat genotypes. Under the condition of 3 soil-water-stress treatments (75\% field capacity (FC), 55\% FC, 45\% FC, named level 1, level 2 and level 3, respectively), pot experiments for them were conducted and the related data were collected from their life circle. The main results were as followed: (1) according to the selected soil stress levels, water use efficiency (WUE) of 10 different wheat genotypes was divided into two groups (A and B); group A included genotypes 2, 3, 4, 5, 6, 7, 8, whose WUE decreased basically from level 1 to level 3 and reached individual peak of WUE at level 1; Group 2 included genotypes 1,9,10, whose WUE reached their individual peak at level 2; (2) based on total water consumption through all life circle, genotypes 1, 4, 8, 9 had lower water consumption (TWC) at level 1, genotypes 2, 3, 5, 6, 7 lower TWC at level 2, genotype 10 lower TWC at level 3 ; (3) at level 1, genotypes 2, 3, 4, 5, 6, 7, 8 had higher grain weight of single spike (GWSS), genotypes 1, 9, 10 better GWSS at level 2, which was in good line with individual WUE of different wheat genotypes; (4) by analyzing the indexes related to examining cultivars, it was found that genotypes 1, 2, 3, 4, 5, 6, 9, 10 had longer plant length (PL), spike length (SL), bigger grain number (GN) except genotypes 7 and 8 at level 1, RL was in better line with genotypes 1,2,3,8,9,10, but not in the other genotypes at level 1 .
\end{abstract}

(c) 2006 Elsevier B.V. All rights reserved.

Keywords: Triticum aestivum L.; Resistance drought; WUE; Anti-oxidative stress; Physiological mechanism; Soil water stress threshold; Anti-drought breeding; Bio-water-saving; Soil-root biointerface

\section{Introduction}

Drought is a worldwide problem, constraining global crop production and quality seriously and recent global climate

\footnotetext{
* Corresponding author at: Biology Department, College of Molecular and Chemical Engineering, Qingdao University of Science and Technology, Qingdao 266042, People's Republic of China. Tel.: +86 53284022506 ; fax: +8653284022757

E-mail address: shaohongbochu@126.com (H.-B. Shao).

${ }^{1}$ Both authors contributed to this paper equally.
}

change has made this situation more serious $[1,2,5,7,10,14$, $16,25-28,34-36,49,65]$. Drought is a complex physicalchemical process, in which many biological macromolecules and small molecules are involved, such as nucleic acids, proteins, carbohydrates, lipids, hormones, ions, free radicals, mineral elements $[3,4,6,8,9,11,12,17,18,23,27,28,34,38-44,48$, $52,60,61,69,70,78]$. In addition, drought is also related to salt stress, cold stress, high temperature stress, acid stress, alkaline stress, pathological reactions, senescence, growth, development, cell circle, UV-B damage, wounding, embryogenesis, flowering, signal transduction and so on $[19,23,26,30,35,38,40-46,57-59]$. 
Therefore, drought is connected with almost all aspects of biology [71,79-83]. Currently, drought study has been one of the main directions in global plant biology and biological breeding. NSF in USA established the program of Plant Genome Functions Under Stresses in 1998, and strengthened it in 2000, and drafted it towards 2010 [15,54]. Just 1 year ago, European Commission, who once kept conservative to biotechnological breeding, constructed a big project: Plants for the Future: a European vision for Plant Biotechnology towards 2025, in which much is involved in resistance drought [14]. Many advances in relation to this hot topic, including molecular mechanism of anti-drought and corresponding molecular breeding have taken place $[28,33,34,39,44,47,50,53,55-56,63,72-75,78]$. Although the obtained transgenic crops (mainly, wheat) by different types of gene technology all exhibit drought resistance to some extent, they have many shortfalls related to agronomical performance and/or development $[47,49,53,62,66,68,74]$. These results imply that systemical, deeper, and comprehensive understanding of physiological mechanism of crops under drought stresses is not enough to manipulate the physiological regulatory mechanism and take advantage of full this potential for productivity, whose study is the bridge between molecular machinery of drought and anti-drought agriculture, because the performance of genetic potential of crops is expressed by physiological realization in fields $[1,2,8,10,53,54]$. Towards this aim, many promising methodologies appear, but they should also be linked with field practice $[12,13,18,24,29,31,40,51,72]$. Wheat is a staple food for more than $35 \%$ of the world population and wheat is also the second grain crop in China, whose production status is directly related to social stability, Chinese survival and sustainable development $[13,21,22,30,37,38,59,65]$. With progressive global climate change and increasing shortage of water resources and worsening eco-environment, wheat production is influenced greatly $[8,38,52]$. Many reports have been related to WUE and production and clearly explained the linear relationship between WUE and production in wheat, maize and other plants [21,22,26,36,37,46,41,76], but little is involved in such aspect of different wheat genotypes. To aim at making different wheat genotypes perform fully physiological potential under limited soil water conditions in fields, by selecting practical materials for direct breeding and establishing an efficient platform for deciphering molecular mechanisms of wheat drought resistance, especially, the link of the redox state with anti-drought, we chose 10 promising wheat genotypes as experimental materials, applied stimulation natural drought and potting cultivation methods, collected related physiological data of whole growth circle (mainly, seedling stage, tillering stage, and maturation stage), and primarily evaluated resistance drought of these genotypes. Here, we reported the related results of WUE and production.

\section{Materials and methods}

\subsection{Plant materials}

Ten wheat genotypes (Xinong9-1-1-13, Xinong-1, Xinong32, Xinong4-2, Xinong9337-1, YB0738, Xiaobingcao7, Jin- mai47, Yumai49, Xiaoyan22, and labeled 1, 2, 3, 4, 5, 6, 7, $8,9,10$, respectively) are from Yangling Breeding Center of National Wheat Engineering Research Center of China.

\subsection{Experimental fields}

The outward potting cultivation field is affiliated to experimental plots of National Key Laboratory of Soil Erosion and Dryland Farming, the Center of Soil and Water Conservation and Eco-environmental Research, Chinese Academy of Sciences. Pots $(35 \mathrm{~cm} \times 27 \mathrm{~cm})$ are made of plastics, whose empty weight was $2 \mathrm{~kg}$ and the full pot weight was $24 \mathrm{~kg}$ according to Wang and $\mathrm{Li}$ [65]. The physical and chemical property of the selected soil is as follows: organic matter $11.2 \mathrm{mg} / \mathrm{g}$, total $\mathrm{N} 0.93 \mathrm{mg} / \mathrm{g}$, available $\mathrm{N} 122.1 \mathrm{mg} / \mathrm{kg}$, effective P $52.2 \mathrm{mg} / \mathrm{kg}$, available K $233.2 \mathrm{mg} / \mathrm{kg}$.

\subsection{Experimental design}

Each genotype was conducted in 3 level soil water treatments controlled by weighting ( $75 \% \mathrm{FC}, 55 \% \mathrm{FC}$, and $45 \% \mathrm{FC}$, respectively) according to Hsiao [25], each of which is six times repeated and matched with 1 empty control, correspondingly.

\subsection{WUE and measurement of production}

According to total consumed water through wheat life circle, WUE was calculated by referring to Gao et al. [20,21]. Production measurement was based on each pot, in which 10 plants were taken for detecting number of grain and spikes and corresponding weight according to $\mathrm{Li}$ et al. [26]. All data were measured three times at the same time and analyzed by Duncan's multiple range test at $p<0.05(n=6)$.

\section{Results}

\subsection{WUE change of 10 wheat genotypes at soil water deficits}

From Fig. 1, it was found that at level 1, genotypes 2-9 expressed higher WUE than that of the other levels, demonstrating that proper soil water supply was beneficial to increase

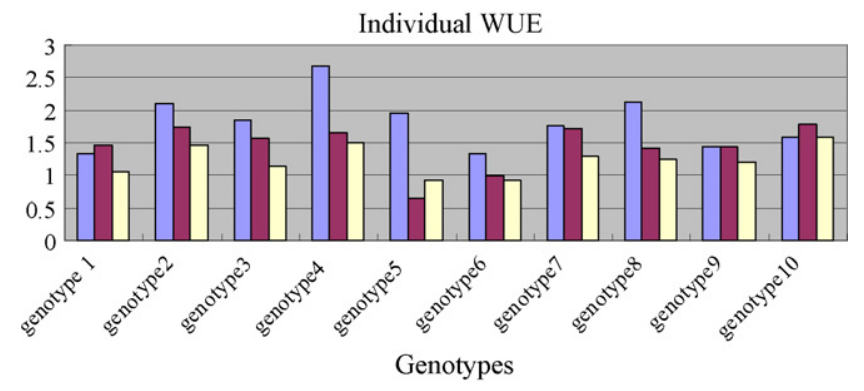

Fig. 1. Individual WUE change of 10 wheat genotypes at soil water deficits. Blue, red and yellow color represent level 1, level 2 and level 3, respectively. (For interpretation of the references to color in this figure legend, the reader is referred to the web version of the article.) 


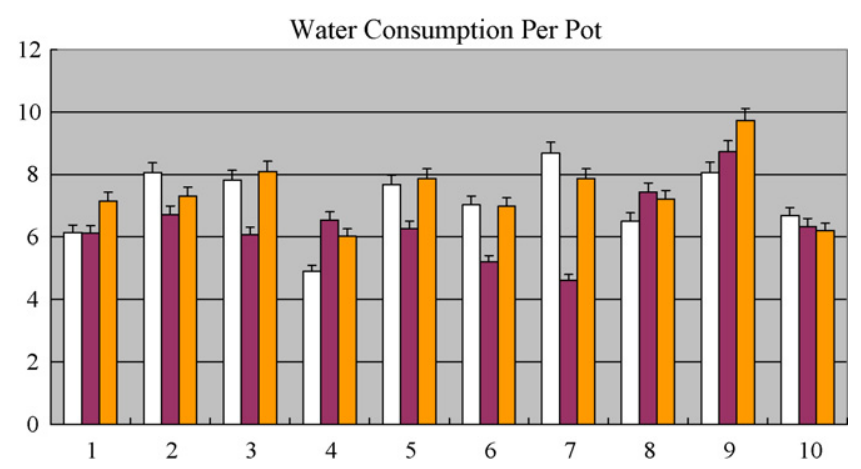

Fig. 2. Total water consumption of 10 wheat genotypes through life circle at soil water deficits. White, red and yellow color represent level 1, level 2 and level 3 , respectively. Numbers 1-10 represent wheat genotypes 1-10, correspondingly. Vertical bars stand for the mean \pm S.E. $(n=6)$. (For interpretation of the references to color in this figure legend, the reader is referred to the web version of the article.)

WUE for most wheat genotypes. At level 2, genotypes 1 and 10 performed better WUE by comparing with level 1 and level 3, implying that these two wheat genotypes could sustain stronger WUE at middle-soil-water-stressed conditions, which provided clues to water-saving agriculture and physiological breeding in arid and semi-arid areas. Genotype 4 had the highest WUE at level 1, genotype 10 the highest WUE at level 2 and level 3 among these 10 genotypes. The phenotype of genotype 10 reflected its history of domestication in flooded areas. Although most genotypes decreased their WUE from level 1 to level 3, their changing degree was different with genotypes. This case was the same in three levels, which further showed that different wheat genotypes had different anti-drought thresholds.

\subsection{Total water consumption (TWC) through wheat life circle for 10 genotypes}

According to Fig. 2, at soil water level 1, genotypes 2, 3, 5, $6,7,10$ had more TWC than that of the other what genotypes. Under the condition of level 2, genotypes 4 and 8 possessed bigger TWC and genotypes 1 and 9 greater TWC at level 3 . This fact basically reflected the WUE trend in Fig. 1, but could not for genotypes $1,4,8,9$, which showed that other factors such as transpiration and photosynthesis (unpublished papers) influenced TWC. At level 1, genotype 7 had the highest TWC, and genotype 9 the greatest TWC at level 2 and 3, which was also related to its characteristics of flooded origin as mentioned in genotype 10 .

\subsection{Grain weight of single spikes (GWSS) of 10 wheat genotypes at soil water deficits}

From Fig. 3, at level 1, genotypes 2-8 had higher GWSS than that of the other genotypes. Under the condition of level 2, genotypes 1 and 9 had greater GWSS. Genotype 2 had the highest GWSS at level 1 and genotype 9 had the biggest GWSS at level 2 and level 3. The result reflected from Fig. 3 was in good line with Fig. 1.

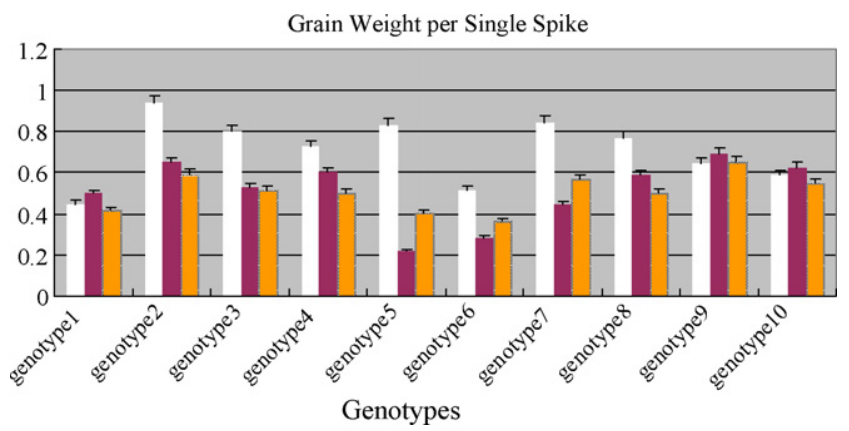

Fig. 3. Grain weight per single spike (GWSS) comparison of 10 wheat genotypes at soil water deficits. White, red and yellow color represent level 1, level 2 and level 3, respectively. Vertical bars stand for the mean \pm S.E. $(n=6)$. (For interpretation of the references to color in this figure legend, the reader is referred to the web version of the article.)

\subsection{Comparison of indexes related to examining wheat cultivars at soil water deficits}

From Table 1, most indexes (plant length, spike length, grain number) related to examining wheat cultivars had a similar changing format for genotypes $1,2,3,5,6,8,10$ at level 1 , in which they had higher value. Under the condition of level 2 , genotype 7 had greater plant length, spike length, and grain number and genotype 9 had bigger plant length and spike length at level 3. It was difficult to find a uniform changing pattern for the other indexes such as root length and inefficient spikelet number. Comparing Figs. 1, 3 and 4, most wheat genotypes basically performed better WUE, production and had stronger plant form at level 1. Genotypes 8, 9, 10 in most cases could expressed relatively stronger ability to respond to soil water stress, implying that these 3 cultivars were from domestication of flooded areas and they have formed a stable anti-oxidative "microenvironment" for combating severe environments outwards.

\section{Discussions}

Plants have evolved a wide range of defense systems to survive continuous assault by an arsenal of biotic attacks, constantly changing weather and other environmental conditions $[35,41,42,45,55,56,61,63,69,73,75,77]$. Unlocking the physiological and molecular basis for the plasticity of plant defending metabolism not only provides access to a largely untapped resource of genes and selection markers for breeding enhanced stress tolerance in crops but also ensures improved food security and agricultural sustainable development worldwide [5,8,10,19,32,44,48,52,62].

Living organisms can be viewed as reducing-oxidising (redox) systems in which catabolic, largely oxidative processes produce energy and anabolic, principally reductive processes assimilate it $[5,35,61,75,77]$. Aerobic organisms exploit the redox potential of oxygen while controlling oxidation, in particular, the plants in arid and semi-arid zones. A key feature determining the size of the plant "physiological window" where metabolic functions can be maintained and regulated, is the extent to which oxidative reactions can be tightly controlled [1]. If environmental changes are too extreme to allow 
Table 1

Comparison of indexes related to examining wheat cultivars at soil water deficits

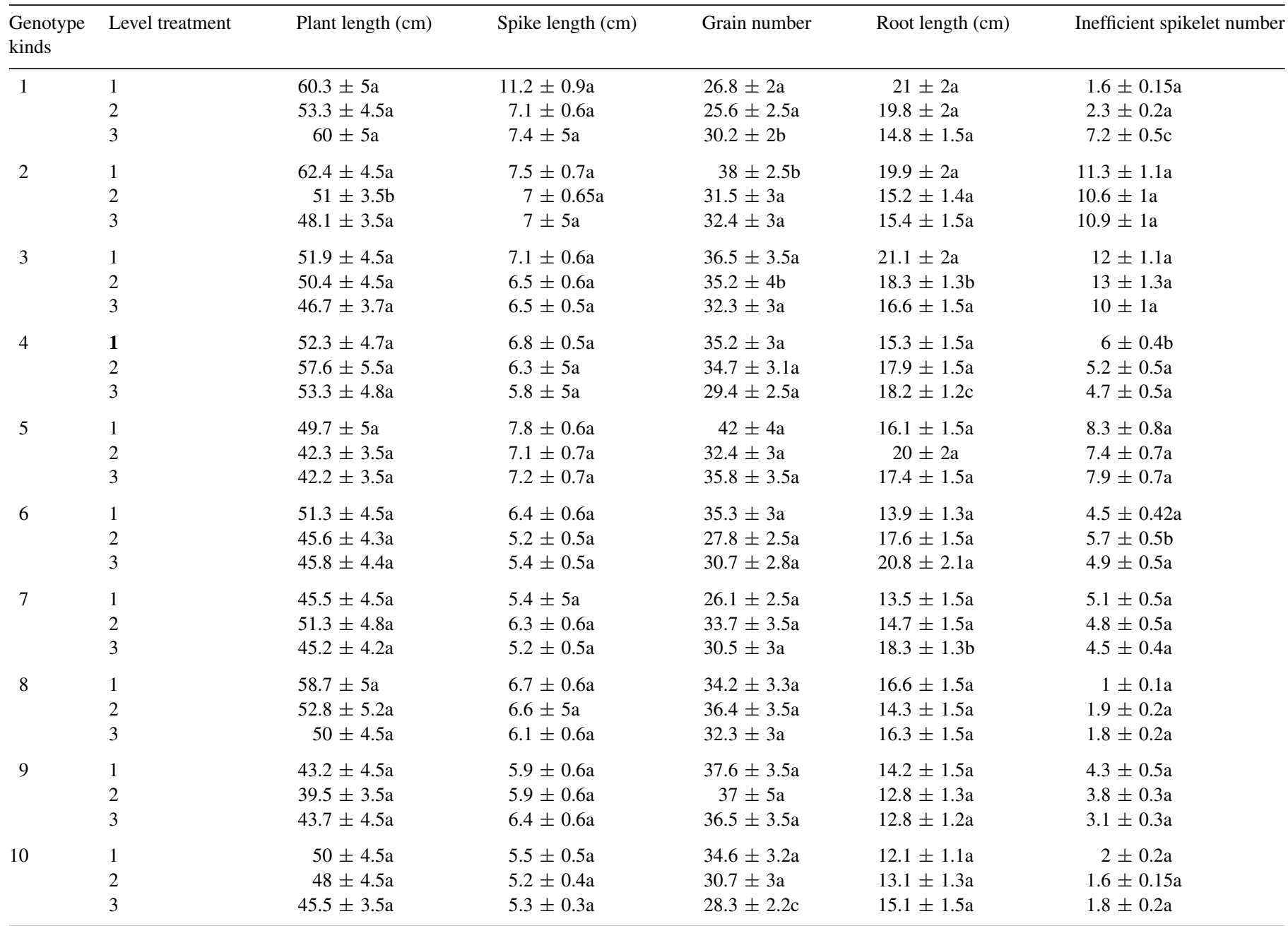

The data followed by the same letters (a-c) are not significantly different within the same row by Duncan's multiple range test at $p<0.05$. Values are the mean of six replicates \pm S.E. (standard error).

short-term metabolic controls to maintain fluxes through primary metabolism while preventing uncontrolled oxidation, then stress-induced damage ensues. Here, there is an obvious stress threshold $[1,58,59]$. In this situation acclamatory changes in gene expression are induced in attempt to restore redox homeostasis $[73,75]$. If the repertoire of genomic responses is not insufficient or not appropriate then primary metabolism is impaired, oxidative stress becomes increasingly important and cell death and senescence responses are triggered [5,59,61]. One of the earliest responses of plants to pathogens, wounding, drought, extremes of temperature or physical and chemical shocks is the accumulation of active oxygen species (AOS) such as superoxide, hydroxyl radicals, hydrogen peroxide and singlet oxygen [35]. The oxidative stress that ensues is a widespread phenomenon $[69,73,75]$. It is observed in wheat exposed to most, if not all, biotic and environmental stresses. AOS are key components contributing to cellular redox poise. They participate in all processes controlled by redox reactions. These include signal transduction, gene expression, protein synthesis and turnover, thiol-disulphide exchange reactions and regulation of metabolism. AOS accumulation is sensed as an 'alarm' signal that initiates pre-emptive defense responses $[4,11,23,52,70]$. Common and linked signal transduction pathways are activated that can lead either to stress acclimation or to cell death depending on the degree of oxidative stress experienced. Wheat responses to stresses are therefore directed to acclimate and repair damage, which is the basic common feature of organisms [3,8,12].

POD, SOD, CAT and MDA are common and important indices for evaluating the status of wheat redox, whose activities of the former 3 and whose lower of MDA display higher anti-oxidative ability, reflecting higher resistance drought $[1,5,48,49]$. In our experiment, our former results showed that different wheat genotypes clearly responded to soil water deficiency differently in terms of activities of POD, SOD, CAT and MDA content [59]. This further implied that different wheat genotypes had discrete water stress threshold and therefore they had different physiological adaptive mechanism to regulate their redox status [35,59]. Obviously, the difference in this aspect exhibited the difference in their alleles of different 
wheat genotypes $[16,19,52,70]$. The emerging methodologies including, genomic approaches, system-oriented ways, largescale microarray technology, genome-metabolite profiling analysis and transcriptom profiling precise annotation, in combination with genetic mutant selection, transgenic strategy and plant physiology, will uncover this network regulatory system of wheat genotypes being adaptive to different soil water stresses [64].

WUE and production are related closely related to the redox state in plants, through which plants complete transportation and conversion of photosynthetic products and their life circle, further making plant physiological potential into full use [21,22,26,71,79-80].

Our results firstly clearly showed that different wheat genotypes differently responded to soil water stress at different stages in terms of physiological mechanisms, implying that they have different soil water stress threshold [59]. Exploring its range and accurate amount of different genotypes is of importance to understanding physiological mechanisms of wheat resistance and tolerance drought and saving-water agriculture by the way of physiological regulation in arid and semi-arid locations. Secondly, our experimental results further demonstrated the fact accepted and adopted by most scholars [25], that $75 \% \mathrm{QF}, 55 \% \mathrm{QF}$, and $45 \% \mathrm{QF}$ is normal, light-stressed, and severe-stressed water level, respectively, is needed to be modified in order to represent the practical level of more plants. Thirdly, WUE was in better concert with production for most wheat genotypes (Figs. 1 and 3) under the conditions of different soil water stresses $[7,8,58,59]$. The results of Gao et al. [21] and Guo et al. [22] by selecting winter wheat cultivars as materials proved this point. Forthly, we also found that the changing trend of WUE and production under our condition of three stress levels is tightly linked with the location of their cultivation, which reflects the change of corresponding alleles of different genotypes under the pressure of natural and artificial selection $[37,77]$. Moreover, this might be linked with evolution of wheat root systems. Kong et al. [30] and Jiang and Ren [36] did some work in maize cultivars and winter wheat cultivars, respectively and ascertained this co-relationship. This point is of importance to plant species selection for eco-environmental construction and crop selection for agricultural sustainable development in arid and semi-arid regions. Knowing the refine physiological nature, in conjunction with natural rainfall status of different locations, is very important to popularize new wheat species and conduct wheat breeding. Fifthly, most indexes related to examining of wheat cultivars (Table 1) provided a solid proof for the corelationship between WUE and production, but the extent was different with different genotypes, which was similar to Wang and $\mathrm{Li}$ [65].

In a word, the study of physiological mechanisms of wheat anti-drought has much work to do. Molecular biology aspects of wheat cannot substitute for this important part, but strengthen the research and provide a broad future and platform. It is easy to see that one cell or molecule cannot be alive in natural fields and not provide any economic effect for human beings. The combination of molecular biology, plant physiology and other related disciplines is the key. Many achievements in biotech- nological and traditional breeding of wheat are good examples. Although some progresses in terms of the exploration of molecular nature of wheat anti-drought also have taken place, many problems exist. Currently, from the view of globe, sustainable development is the key point. The necessary way to solve the issue of sustainable development is by biological measures, in which plants will play greater roles and crops will play the greatest functions with no doubt [62]. To aim at taking advantage of full use of crop physiological potential for high production and safe food with better quality, the followed problems remain to be known. What is the relationship of mineral elements (in particular, $\mathrm{K}^{+} \mathrm{Na}^{+}$in soils) with root signal transduction (pathways)? Much of former study showed that $\mathrm{K}^{+}$was little connected with anti-drought, but recent research and our results displayed that it was linked with wheat resistance drought $[3,7,39,60,66,67,75]$. What is the exact soil water stress threshold of individual wheat genotype? This is of much importance to resistance drought breeding and saving-water agriculture and precise agriculture under global climate change. What are the details that constitute the network regulatory system of drought, cold, UV-B, freezing, acidity, salty, wounding, pathogen, senescence, cell death? How is each linked with other parts? What is the (transient) connection among different physiological adaptive regulatory pathways at different levels? What role do endogenous hormones play in this course? What is the crosstalk among them when abiotic or/and biotic stress happens? The redox state in plants is important, and how is it regulated by drought signal? What is the best allocation of different crops and grass-shrub-forest in worsening arid and semi-arid areas for obtaining economic and ecological effect? A widespread use of data resources for fine gene functions and structure of different plants (species) is from model plants, Arabidopsis thaliana and rice, and how large is the reliability [79-83]? No doubt, expanded detecting of plant range is more urgent. So, we think that physiological studies at different scales have much work to do with the increasing atmospheric change.

\section{Acknowledgement}

This work is jointly supported by Initiation Foundation of Excellent Ph.D. Dissertation of Chinese Academy of Sciences, Qingdao University of Science and Technology (0022221) (to H.B. Shao) and Natural Science Foundation of China (No. 40473054) (to G. Wu).

Many thanks are given to our post-graduate students, Mr. H.L. Zhuang, F.L. Chen, M. Zhou, X.R. Kong, Ms. J. Zhang, J.F. Yu, and Y.J. Shong for their help in field experiments.

\section{References}

[1] K. Apel, A. Hirt, Reactive oxygen species: metabolism, oxidative stress, and signal transduction, Ann. Rev. Plant Biol. 55 (2004) 373-399.

[2] A. Anand, H.N. Gill, B.S. Trick, Stable transgene expression and random gene silencing in wheat, Plant Biotechnol. J. 1 (4) (2003) 241-251.

[3] B. Bartel, D.P. Bartel, MicroRNAs: at the root of plant development? Plant Physiol. 132 (2003) 709-717.

[4] P. Casati, V. Walbot, Rapid transcriptome responses of maize (Zea mays) to UV-B irradiated and shielded tissues, Genome Biol. 5 (2004) R16-R28. 
[5] Z. Chen, D.R. Gallie, The ascorbic acid redox state controls guard cell signaling and stomatal movement, Plant Cell 16 (2004) 1143-1162.

[6] T. Capell, L. Bassie, P. Christou, Modulation of the polyamine biosynthetic pathway in transgenic rice confers tolerance to drought stress, PNAS 101 (26) (2004) 9909-9914.

[7] J.W. Chandler, D. Bartels, Drought avoidance and drought adaptation, Encyclopedia Water Sci. (2003) 163-165.

[8] M.M. Chaves, J. Maroco, J. Pereira, Understanding plant responses to drought-from genes to the whole plant, Funct. Plant Biol. 30 (2003) 239-264.

[9] S.A. Casson, K. Lindsey, Genes and signaling in root development, New Phytol. 158 (1) (2003) 11-34.

[10] J.C. Cushman, J. Bohnert, Genomic approaches to plant stress tolerance, Curr. Opin. Plant Biol. 3 (2) (2000) 117-124.

[11] S. Dhanda, G.S. Sethi, R.K. Behl, Indices of drought tolerance in wheat genotypes at early stages of plant growth, J. Agron. Crop Sci. 190 (1) (2004) 6-12.

[12] C. Delessert, I.W. Wilson, D. Van Der Straiten, Spatial and temporal analysis of the local response to wounding in Arabidopsis leaves, Plant Mol. Biol. 51 (2004) 1-18 (uncorrected proof).

[13] L.J. Dai, Z.Q. Li, Comparative and functional genomics of wheat, Acta Bot. Boreal-Occident Sin. 24 (5) (2004) 949-953.

[14] European Commission, Plants for the future: A European Vision for Plant Genomics and Biotechnology towards 2025 (see the web site: www.europabio.org/), 2004.

[15] Editor's choice, The National Plant Genomics Initiative: objectives for 2003-2008. Plant Physiol. 130 (2002) 1741-1744.

[16] L. Erdei, I. Tari, J.I. Csiszar, Osmotic stress responses of wheat species and cultivars differing in drought tolerance: some interesting genes (advices for gene hunting), in: Proceedings of the 7th Hungarian Congress on Plant Physiology S2-O6, 2002.

[17] W. Fricke, G. Akhiyarova, D. Veselov, Rapid and tissue-specific changes in ABA and in growth rate in response to salinity in barley leaves, J. Exp. Bot. 55 (399) (2004) 1115-1123.

[18] O. Fiehn, Metabolomics-the link between genotypes and phenotypes, Plant Mol. Biol. 48 (2002) 155-171.

[19] C. Glombitza, P.H. Dubuis, O. Thulke, Crosstalk and differential response to abiotic and biotic stressors reflected at the transcriptional level of effector genes from secondary metabolism, Plant Mol. Biol. 51 (2004) 1-19 (uncorrected proof).

[20] J.F. Gao (Editor-in-Chief), Experimental Technology in Plant Physiology. World Books Publishing Company, Xi'an, China, 2000.

[21] S.J. Gao, W.J. Wang, T.C. Guo, C-N metabolic characteristics in flag leaf and starch accumulating developments in seed during grain filling stage in two winter wheat cultivars with different spike type, Acta Agron. Sin. 29 (3) (2004) 427-431.

[22] T.C. Guo, W. Feng, H.J. Zhao, Photosynthetic characteristics of flag leaves and nitrogen effects in two winter wheat cultivars with different spike type, Acta Agron. Sin. 30 (2) (2004) 115-121.

[23] J.A. Hernandez, C. Escobar, G. Creissen, Role of hydrogen peroxide and the redox state of ascorbate in the induction of antioxidant enzymes in pea leaves under excess light stress, Funct. Plant Biol. 31 (4) (2004) 359-368.

[24] M.Y. Hiral, M. Yano, D.B. Goodenowe, Integration of transcripomics and metabolomics for understanding of global responses to nutritional stresses in Arabidopsis, PNAS 101 (26) (2004) 1-6.

[25] T.C. Hsiao, Plant response to water stress, Ann. Rev. Plant Physiol. 24 (1973) 519-534

[26] Y.H. Li, W. Wang, Q.J. Ma, The osmotic adjustment and photosynthesis of a wheat cultivar Hanfeng 9703 with high yield, drought resistance under drought stress, Acta Agron. Sin. 29 (5) (2003) 759-764.

[27] Y.S. Liu, S.I. Roof, Z.B. Ye, Manipulation of light signal transduction as a means of modifying fruit nutritional quality in tomato, PNAS 101 (26) (2004) 9897-9902.

[28] X.N. Liu, W.M. Vance Baird, Identification of a novel gene, HAABRC5, from Helianthus annuus (Asteraceae) that is upregulated in response to drought, salinity, and abscisic acid, Am. J. Bot. 91 (2004) 184-191.

[29] J. Kopka, A. Fernie, W. Weckwerth, Metabolite profiling in plant biology: platforms and destinations, Genome Biol. 5 (2004) 109-125.
[30] Q.Q. Kong, C.H. Hu, S.T. Dong, Evolution of root characters during all growth stage of maize cultivars in different eras in China, Acta Agron. Sin. 29 (5) (2003) 641-645.

[31] H. Kitano, Looking beyond the details: a rise in system-oriented approaches in genetics and molecular biology, Curr. Genet. 41 (1) (2002) 1-10.

[32] M. Kern, Food, feed, fibre, fuel and industrial products of the future: Challenges and Opportunities. Understanding the strategic potential of plant genetic engineering, J. Agron. Crop. Sci. 188 (5) (2002) 291302

[33] M. Kasuga, Q. Liu, S. Miura, Improving plant drought, salt, and freezing tolerance by gene transfer of a single-inducible transcription factor, Nat. Biotech. 17 (3) (1999) 287-291.

[34] J.A. Kreps, Y.J. Wu, H.S. Chang, Transcriptome changes for Arabidopsis in response to salt, osmotic, and cold stress, Plant Physiol. 130 (2002) 2129-2141.

[35] M.Y. Jiang, J.H. Zhang, Abscisic acid and antioxidant defense in plant cells, Acta Bot. Sin. 46 (1) (2004) 1-9.

[36] S.F. Jiang, X.P. Ren, The effect on SOD activity and protein content in groundnut leaves by drought stress, Acta Agron. Sin. 30 (2) (2004) 169-174.

[37] R.L. Jing, X.P. Chang, Genetic diversity in wheat (T. aestivum) germplasm resources with drought resistance, Acta Bot. Boreal-Occident Sin. 23 (3) (2003) 410-416.

[38] D. Jiang, Z.J. Xie, W.X. Cao, Effects of post-anthesis drought and waterlogging on photosynthetic characteristics, assimilates transportation in winter wheat, Acta Agron. Sin. 30 (2) (2004) 175-182.

[39] F.J.M. Maathuis, V. Filatov, P. Herzyk, Transcriptom analysis of root transporters reveals participation of multiple gene families in the response to cation stress, Plant J. 35 (2003) 675-692.

[40] C. Mlot, Plant biology in the genome era, Science 281 (5375) (1998) 331-332.

[41] R. Munns, Comparative physiology of salt and water stress, Plant Cell Environ. 25 (2) (2002) 239-252.

[42] J.M. Morgan, Plants: osmotic adjustment, Encyclopedia Water Sci. (2003) 692-695.

[43] E.M. Meyerowitz, Plants compared to animals: the broadest comparative study of development, Science 295 (5559) (2002) 1482-1485.

[44] E. Mantyla, V. Lang, T. Palva, Role of abscisic acid in drought-induced freezing tolerance, cold acclimation, and accumulation of LT178 and RAB18 proteins in Arabidopsis, Plant Physiol. 107 (1995) 141-148.

[45] P. Neumann, Salinity resistance and plant growth revisited, Plant Cell Environ. 20 (1997) 1193-1198.

[46] F.X. Niu, X.X. Hua, X.D. Guo, Studies on several physiological indexes of the drought resistance of sweet potato and its comprehensive evaluation, Acta Agron. Sin. 22 (4) (1996) 392-398.

[47] D. Patnaitk, P. Khurana, Wheat biotechnology: A minireview, EJB Electron J. Biotechnol. 4 (2) (2001) 74-102.

[48] Z. Plaut, Crop plants: critical development stages of water, Encyclopedia Water Sci. (2003) 95-100.

[49] A. Pellegrineschi, J.M. Ribaut, R. Trethowan, Progress in the genetic engineering of wheat for water-limited conditions, JIRCAS Working Rep. (2002) 55-60.

[50] T. Puhakainen, M.W. Hess, P. Makela, Overexpression of multiple dehydrin genes enhances tolerance to freezing stress in Arabidopsis, Plant Mol. Biol. 51 (2004) 1-11 (uncorrected proof).

[51] A. Rellegrineschi, J.M. Ribaut, N.R. Trethowan, Looking beyond the details: a rise in system-oriented approaches in genetics and molecular biology, Curr. Genet. 41 (1) (2002) 1-10.

[52] J. Saba, M. Moghaddam, K. Ghassemi, Genetic properties of drought resistance indices, J. Agric. Sci. Technol. 3 (2001) 43-49.

[53] X. Shou, P. Bordallo, K. Wang, Expression of the Nicotiana protein kinase (NPK1) enhanced drought tolerance in transgenic maize, J. Exp. Bot. 55 (399) (2004) 1013-1019.

[54] C. Somerville, J. Dangl, Plant biology in 2010, Science 290 (4599) (2000) 2077-2078.

[55] K. Shinozaki, E.S. Dennis, Cell signaling and gene regulation global analyses of signal transduction and gene expression profiles, Curr. Opin. Plant Biol. 6 (5) (2003) 405-409. 
[56] K. Shinozaki, K. Yamaguchi-Shinozaki, M. Seki, Regulatory network of gene expression in the drought and cold stress responses, Curr. Opin. Plant Biol. 6 (5) (2003) 410-417.

[57] H.B. Shao, Z.S. Liang, M.A. Shao, Impacts of PEG-6000 pretreatment for barley (Hordeum vulgare L) seeds on the effect of their marure embryo in vitro culture and primary investigation on its physiological mechanism, Colloids Surf. B: Biointerf. 41 (2-3) (2005) 73-77.

[58] H.B. Shao, Z.S. Liang, M.A. Shao, Roles of ABA signal transduction during higher plant seed maturation and germination, Forestry Stud. China 5 (4) (2003) 42-51.

[59] H.B. Shao, Z.S. Liang, M.A. Shao, Changes of some physiological and biochemical indices for soil water deficits among 10 wheat genotypes at seedling stage, Colloids Surf. B: Biointerf. 42 (2) (2005) 107-113.

[60] Z.C. Tang, Responses and adaptation of plants to water stress, Plant Physiol. Commun. (4) (1983) 1-7.

[61] I. Urquiaga, F. Leighton, Plant polyphenol antioxidants and oxidative stress, Biol. Res. 33 (2) (2000) 59-75.

[62] I.K. Vasil, The science and politics of plant biotechnology-a personal perspective, Nat. Biotech. 21 (8) (2003) 849-851.

[63] A. Villalobos, D. Bartels, G. Iturringa, Stress tolerance and glucose insensitive phenotypes in Arabidopsis overexpressing the CpMYB10 transcription factor gene, Plant Physiol. 135 (2004) 309-324.

[64] P. Wenzl, J. Carling, D. Kudrma, Diversity arrays technology (DArT) for whole-genome profiling of barley, PNAS 101 (26) (2004) 9915-9920.

[65] J.R. Wang, S.X. Li, Effect of water-limited deficit stress in different growth stages on winter wheat grain yields and their yield constituents, Acta Bot. Boreal-Occident Sin. 20 (2) (2000) 193-200.

[66] H. Wang, Z.J. Huang, Q. Chen, Ectopic overexpression of tomato JERF3 in tobacco activates downstream gene expression and enhances salt tolerance, Plant Mol. Biol. 151 (2004) 1-10 (uncorrected proof).

[67] X.D. Wang, Z.W. Yu, D. Wang, Effect of potassium on flag leaf proteinases activity and kernel quality in wheat, Acta Agron. Sin. 29 (2) (2003) 285-289.

[68] W.X. Wang, P. Vinocur, A. Altman, Plant responses to drought, salinity and extreme temperatures: towards genetic engineering for stress tolerance, Planta 218 (1) (2003) 1-14.

[69] S.W. Yu, K.X. Tang, MAP kinase cascades responding to environmental stress in plants, Acta Bot. Sin. 46 (2) (2004) 127-136.
[70] I. Yordanov, V. Velikova, T. Tsonev, Plant responses to drought and stress tolerance, Bulg. J. Plant Physiol. (Special issue) (2003) 187-206.

[71] J.H. Zhu, H.Z. Shi, B.H. Lee, An Arabidopsis homeodomain transcription factor gene, HOS9, mediates cold tolerance through a CBF-independent pathway, PNAS 101 (26) (2004) 9873-9878.

[72] T. Zhu, Global analysis of gene expression using GeneChip microarrays, Curr. Opin. Plant Biol. 6 (5) (2003) 418-425.

[73] J.K. Zhu, Salt and drought stress signal transduction in plants, Annu. Rev. Plant Biol. 53 (2000) 247-273.

[74] F.Y. Zhao, S.L. Guo, Z.L. Wang, Recent advances in study on transgenic plants for salt tolerance, J. Plant Physiol. Plant Mol. Biol. 29 (3) (2003) 171-178.

[75] J.K. Zhu, Regulation of ion homeostasis under salt stress, Curr. Opin. Plant Biol. 6 (5) (2003) 441-445.

[76] M. Zhiponova, L. Szilaz, L. Erdei, Comparative approach for the isolation of genes involved in the osmotolerance of wheat, Acta Biol. Sged. 46 (1-2) (2002) 19-26.

[77] J.X. Zhang, M.B. Kirham, Drought stress-induced changes in activities of superoxide dismutase, catalase, and peroxidase in wheat species, Plant Cell Physiol. 35 (5) (1994) 785-791.

[78] M.S. Zhang, Z.H. Peng, B. Xie, Relationship between water loss rate of cutting leaves and osmotic regulators under water stress and drought resistance in sweet potato, Scientia Agric. Sin. 37 (1) (2004) 152-156.

[79] G.D. Farquhar, R.A. Richards, Isotopic Composition of Plant Carbon Correlates With Water-Use Efficiency of Wheat Genotypes, Aust. J. Plant Physiol. 11 (6) (1984) 539-552.

[80] R.K. Liu, Z.Z. Li, J.H. Zhu, X.H. Zhang, Phosphate buffers effect on protective enzyme system and relationship of enzyme system with $\mathrm{SO}_{2}$ pollution in wheat seedlings, Acta Bot. Sin. 44 (2002) 913-919.

[81] G.J. Rebetzke, A.J. Condon, R.A. Richards, G.D. Farquhar, Selection for reduced carbon isotope discrimination increases aerial biomass and grain yield of rainfed bread wheat, Crop Sci. 42 (2002) 739-745.

[82] C.C. Chen, W.A. Payne, R.W. Smiley, M.A. Stoltz, Yield and water-use efficiency of eight wheat cultivars planted on seven dates in northeastern oregon, Agron. J. 95 (2003) 836-843.

[83] van den Boogaard, T.S. Gahoonia, N.E. Nielsen, Variation in acquisition of soil phosphorus among wheat and barley genotypes, Plant Soil 178 (2) (1996) 223-230. 